\title{
Staying on target
}

\author{
J. Loyal · R. Bergamaschi
}

Received: 21 August 2014/ Accepted: 26 August 2014/Published online: 4 November 2014

(C) Springer-Verlag Italia Srl 2014

\section{Dear Sir,}

We read with great interest the paper by Kipling et al. [1] regarding laparoscopic extralevator abdominoperineal excision (EL-APE) of the rectum. Although we commend the authors' intention to study the use of laparoscopy with regard to EL-APE, we feel compelled to note that the study fails to add anything novel to the existing literature. It is known to the well-informed reader that laparoscopic nonEL-APE does not decrease the rate of involved circumferential resection margin (CRM) [2]. In fact, in Kipling et al.'s study, $11 \%$ of patients had a CRM of less than $1 \mathrm{~mm}$ and $14 \%$ of patients a CRM of $1-2 \mathrm{~mm}$. Moreover, it is unclear in the methods whether the dissection around the cancer was carried out laparoscopically or from the perineum, and regretfully, the size of the tumor was not reported. Emerging evidence has suggested that robotic APE resulted in a greater CRM when compared to the laparoscopic or open counterpart in matched cases by the same surgeon [3].

Upon detailed inspection, it should be pointed out that the authors included patients with $\mathrm{T} 2$ rectal cancer in this study, which appears to be over treating these patients since by definition $\mathrm{T} 2$ rectal cancer does not [4] involve the anal sphincters-perhaps an intersphincteric resection (ISR) should have been considered.
While the last word on EL-APE will be awaiting the completion of the REAPE multicenter trial [5], it should be underscored that although a laparoscopic approach affords a faster recovery time, the primary goal of improving CRM should reign supreme.

Conflict of interest None.

\section{References}

1. Kipling SL, Young K, Foster JD et al (2014) Laparoscopic extralevator abdominoperineal excision of the rectum: short-term outcomes of a prospective case series. Tech Coloproctol $18: 445-451$

2. Raftopoulos I, Reed JF, Bergamaschi R (2011) Circumferential resection margin involvement after laparoscopic abdominoperineal excision for rectal cancer. Colorectal Dis 14:431-437

3. Barnajian M, Pettet D, Kazi E et al (2014) Quality of total mesorectal excision and depth of circumferential resection margin in rectal cancer: a matched comparison of the first 20 robotic cases. Colorectal Dis 16:603-609

4. Compton CC, Greene FL (2004) The staging of colorectal cancer: 2004 and beyond. CA Cancer J Clin 54:295-308

5. Stony Brook University. Extralevator versus standard abdominoperineal resection for rectal adenocarcinoma. In: ClinicalTrials.gov [Internet]. Bethesda (MD): National Library of Medicine (US). 2000-[cited 2014 Aug 12]. http://clinicaltrails.gov/show/ NCT01702116. NLM Identifier: NCT01702116
J. Loyal · R. Bergamaschi $(\bowtie)$

Division of Colon and Rectal Surgery, State University of New York, Health Science Center T18, Suite 046B, Stony Brook, NY 11794-8191, USA

e-mail: rcmbergamaschi@gmail.com 